Mirai. Estudios Japoneses

ISSN-e: 2531-145X

\title{
Monumentos y nación. Kioto como símbolo del espíritu japonés durante el período Meiji
}

\author{
Daniel Sastre de la Vega ${ }^{1}$
}

Fechas

Resumen: Durante el período Meiji la ciudad de Kioto, tras la pérdida de su capitalidad, se enfrentó al reto de competir frente a la nueva capital, Tokio, también con el traslado del emperador y su séquito a la región de Kantō. Una de las estrategias que usó para relanzar su actividad fue la organización de diferentes actividades industriales y de ingeniería civil que transformaron los modos de vida de sus ciudadanos. La segunda estrategia, que sus élites culturales y políticas promovieron al hilo de las políticas de construcción de una nación-estado, fue la configuración simbólica de la ciudad y sus alrededores como el origen espiritual del país. Una ciudad que había preservado durante decenas de generaciones los valores e ideales que configuraban lo que significaba ser japonés. La materialización de estas políticas tuvo en los viajes a los monumentos de la capital por parte de los estudiantes de primaria y secundaria un buen ejemplo, y logró al mismo tiempo educar a los ciudadanos del posterior imperio japonés estableciendo un imaginario colectivo del pasado nacional. Guías de viaje y libros sobre los lugares imprescindibles en las visitas a la ciudad serían algo habitual en el período Taishō cuando la ciudad se había convertido ya en el destino preferente de los visitantes nacionales y foráneos, y la imagen de Kioto como el repositorio de la nación, se había visto completada.

Palabras clave: Kioto; capital; modernidad; Meiji; identidad

\section{[en] Monuments and nation. Kyoto as a symbol of the Japanese spirit during the Meiji period.}

\begin{abstract}
During the Meiji period the city of Kyoto faced the challenge of competing against the new capital of Tokyo after losing its capital status with the move of the Emperor and its entourage to the Kantō region. One of the strategies used in order to re-launch its activity was the organization of different industrial and civil engineering activities, which transformed the way of life of its citizens. The second strategy, promoted by the city's cultural and political elites, and fostered by the national policies of building a nation-state, was the symbolic configuration of the city and its surroundings as the spiritual origin of the country: a city which had preserved during several generations the values and ideals that shaped what it meant to be Japanese. The realization of these policies took place, for instance, in the trips to the monuments of the capital by primary and secondary schools. At the same time, it was an education process for the future citizens of the Japanese Empire by helping them establish a collective imaginary of the national past. Travel guides and books on the places not to miss while in the ancient capital would be fairly common during the Taishō period when the city was already the favourite destination for national and foreign visitors, and the image of Kyoto as the repository of the nation was completed.
\end{abstract}

Keywords: Kyoto; capital; modernity; Meiji; identity

1 Centro de Asia Oriental. Universidad Autónoma de Madrid

daniel.sastre@uam.es 
Sumario: Introducción. La adaptación a la modernidad. Kioto, repositorio de la esencia nacional. Conclusión.

Cómo citar: Sastre de la Vega, D. (2018). Monumentos y nación. Kioto como símbolo del espíritu japonés durante el período Meiji, en Mirai. Estudios Japoneses 2(2018), 21-33.

\section{Introducción}

El período Meiji fue testigo de una de las transformaciones más sistemáticas de los aspectos sociales de la historia japonesa. Muchos de estos cambios traerían consigo una alteración de los paisajes urbanos de sus ciudades. El caso más significativo fue el de la nueva capital, Tokio, que tras su nombramiento como tal en 1868, pasaría a erigir edificaciones en ladrillo, líneas férreas que atravesaban sus barrios, estructuras de estilo occidental así como líneas telegráficas que delineaban una modernidad visual a sus habitantes. ${ }^{2}$

Frente a la vitalidad de este nuevo Tokio, la anterior sede de la casa imperial, la ciudad de Kioto, parecía encontrarse estancada. Al golpe de ver desplazado el gobierno a Tokio, se le sumó al año siguiente el golpe del traslado del emperador, un joven de 16 años, y su corte, a la nueva capital en mayo de $1869 .{ }^{3}$ La ciudad enfrentaba su nueva condición como una ciudad japonesa más. La pérdida de la presencia simbólica de la Casa Imperial y el aspecto práctico que suponía la marcha de todas las casas nobiliarias importantes con ella, dejó en el centro de la ciudad un vacío literal- ya que tanto el palacio como las zonas aledañas se quedaron desiertas. En numerosos casos, se desmontaron parte de las casi doscientas residencias nobiliarias que existían dentro del recinto del Palacio Imperial en Kioto para trasladarlas hasta Tokio. ${ }^{4}$ Dejaban atrás grandes solares en ocasiones todavía ocupados por aquellas estructuras que les eran innecesarias. El movimiento de personas no se limitó tan sólo a las clases altas ya que muchos de los artesanos y miembros del servicio de las diferentes casas también se desplazaron. Se estima que durante el período Edo, Kioto llegó a tener hasta 410.000 habitantes. ${ }^{5}$ La marcha del emperador se tradujo en una caída de población que se quedó en torno a los 230.000 habitantes. ${ }^{6}$

2 En el caso de la ciudad de Tokio y su re-significación frente a la imagen de Edo, así como su configuración como metrópolis internacional a partir de Meiji véase García Montiel, Emilio (1998) Muerte y Resurrección de Tokio. Arquitectura y Urbanismo, 1868-1930. México, D.F.: El Colegio de México. El autor quiere agradecer al par ciego encargado de la revisión de este artículo por sus valiosas apreciaciones en relación al contenido de este artículo.

3 Dougill, John (2006): Kyoto. A Cultural History. Oxford: Oxford University Press, p. 197. Donald Keene ha reflejado como existía cierto temor entre los miembros del Gobierno y seguramente el propio Emperador Meiji de proclamar oficialmente el cambio de capital. De acuerdo a su investigación, no existió dicha orden y Keene proclama: «Podría incluso argumentarse, en la ausencia de una proclamación, por lo contrario, que Kioto permanece a día de hoy la capital de Japón». Keene, Donald (2002): Emperor of Japan. Meiji and His World, 1852-1912. New York: Columbia University Press, p.189. Todas las traducciones son del autor a no ser que se indique lo contrario.

$4 \quad$ Tseng, Alice (2016): "Urban Parks and Imperial Memory. The Formation of Kyoto Imperial Garden and Okazaki Park as sites of cultural revival". En: Pitelka, Morgan / Tseng, Alice (eds.), Kyoto Visual Culture in the Early Edo and Meiji Periods: The Art of Reinvention. London \& New York, Routledge, p.98.

5 Brumann, Christoph (2012): Tradition, Democracy and the Townscape of Kyoto. Claiming a Right to the Past. London \& New York: Routledge, p.47.

$6 \quad$ Ibid., p.48. 
Desde muy pronto los miembros de las élites políticas y económicas de la ciudad fueron conscientes de la necesidad de influir de un modo positivo en el ambiente que se respiraba en ella. Hasta ese momento, la ciudad de Kioto había sido "la capital" por antonomasia. Desde su fundación en el siglo VIII d.C. no habían importado los numerosos vaivenes políticos ya que siempre había permanecido la sede de la corte imperial en ella. Esto le había valido la denominación de miyako (京) o “capital”. El historiador Sonoda Hidehiro ha definido cómo el concepto de miyako posee tres significados básicos: la ubicación del palacio del emperador, del gobierno central, y de una gran masa de gente. ${ }^{7}$ De modo, que el término “(...) define a Kioto en su momento originario como Heian-kyō, en el momento cuando era el centro cultural, económico y político indiscutible de Japón", como relata Alice Tseng. ${ }^{8}$ Los cambios a esta identidad se darían con la llegada del primer bakufu en Kamakura en el siglo XII y la alteración de la autoridad política a Edo en el siglo XVII. En 1869 con el traslado también del emperador, y con la transferencia de personas que con ello se produjo, estas condiciones se perdieron y Tseng ha denominado el comienzo de la etapa de Kioto como una "capital jubilada". ${ }^{9}$ Una ciudad que ha delegado sus funciones políticas a Tokio y que desde la distancia observa el transcurrir del tiempo.

\section{La adaptación a la modernidad}

Las élites políticas locales de la ciudad y una clase comerciante adinerada entendieron que la ciudad debía ponerse al día con los avances de su tiempo si querían sobrevivir. De modo que la primera estrategia que se estableció para la redefinición de Kioto en la nueva era fue la de la modernización tecnológica. ${ }^{10}$ Diferentes proyectos lograrían que en la ciudad se vieran la primera estación hidroeléctrica, los primeros trabajos de ingeniería civil a gran escala, el primer ayuntamiento de estilo occidental, la primera proyección cinematográfica, los primeros tranvías o la primera orquesta sinfónica. ${ }^{11}$ Sin duda, el gran proyecto que marcó la iconografía de la modernidad en la ciudad sería el proyecto del gran Canal de Biwako (1885-1890) ${ }^{12}$ (琵琶湖疎水) (Fig.1) Salvando la cadena montañosa de las colinas orientales de la ciudad llevaba el agua desde el lago de Biwa al otro lado de la ciudad, solucionándolo en ocasiones con la importación de estructuras occidentales como el acueducto en el recinto del Templo Nanzen-ji (南禅寺) (Fig.2) También, permitía el paso de embarcaciones mediante un sistema de remolque desde el lago a la red de canales de la ciudad, y proveía la instalación de una planta hidroeléctrica que generaba la energía con la que se movían los tranvías de la ciudad (los primeros del país). El agua que trajo también

Citado por Tseng, Alice (2012): “The Retirement of Kyoto as Imperial Capital”. En: The Court Historian. The International Journal of Court Studies. Vol.17, N.2, London, pp. 209-213. p. 211.

Íbidem.

$9 \quad$ Ibid., pp. 211-212.

10 Stavros, Matthew (2014): Kyoto. An Urban History of Japan's Premodern Capital. Honolulu: University of Hawai'i Press, p. 182.

11 Dougill, 2006: p. 198.

12 Kobayashi Takehiro (小林丈広) (2012): “Chizude yomu Kyōto・Okazaki Nendai-shi” (『地図で読む京都・岡 崎年代史』) Kioto: Kyōto Okazaki Miryoku Zukuri Suishin Kyōgi-kai (京都岡崎魅力づくり推進協議会), pp.6-

7. Dougill, 2006: pp.198-199. 
aumentó la irrigación de las parcelas y los canales aumentaron su valor como medio de transporte de mercancías. ${ }^{13}$

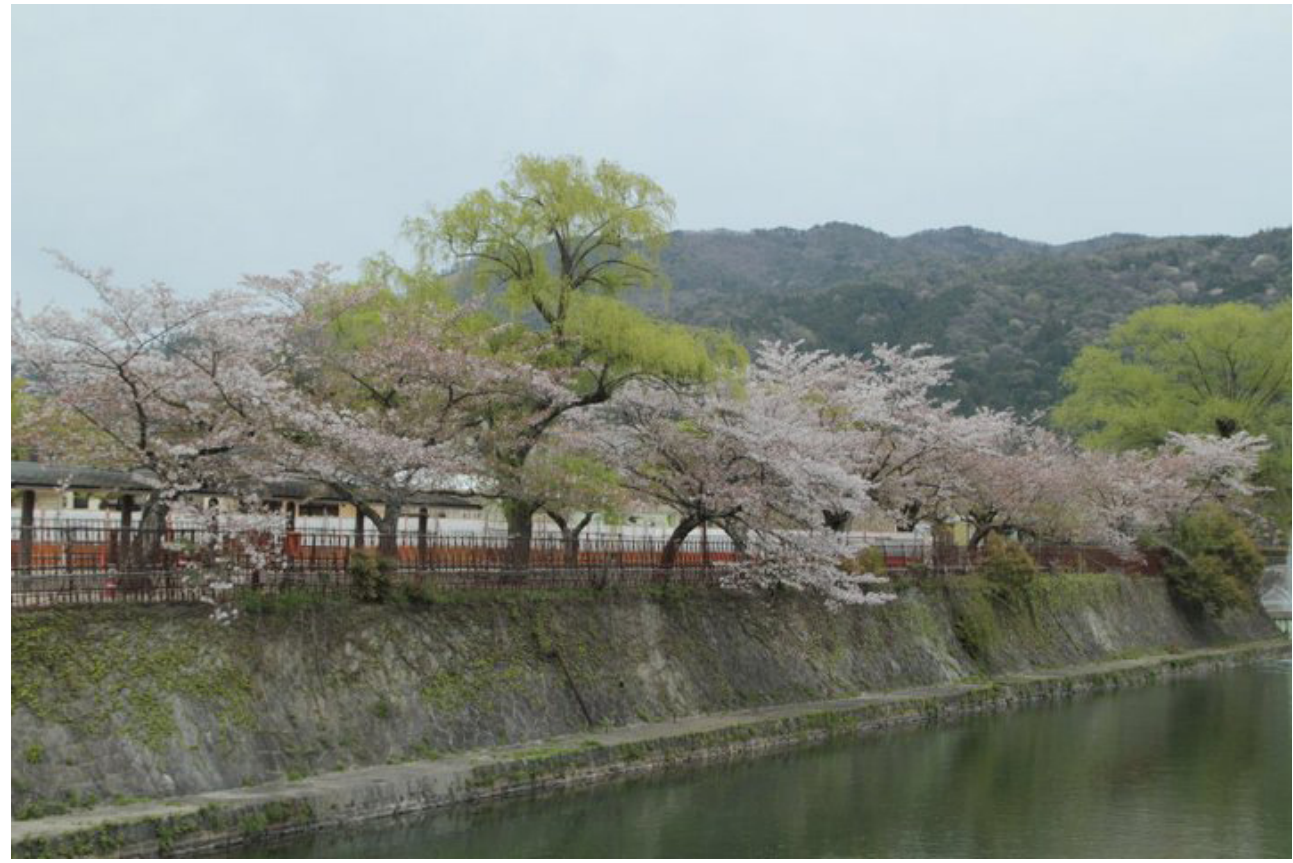

Fig. 1. Canal de Biwa. 1885-1890. Ingeniero jefe: Tanabe Sakurō (1861-1944) Kioto. Foto: Daniel Sastre (2011).

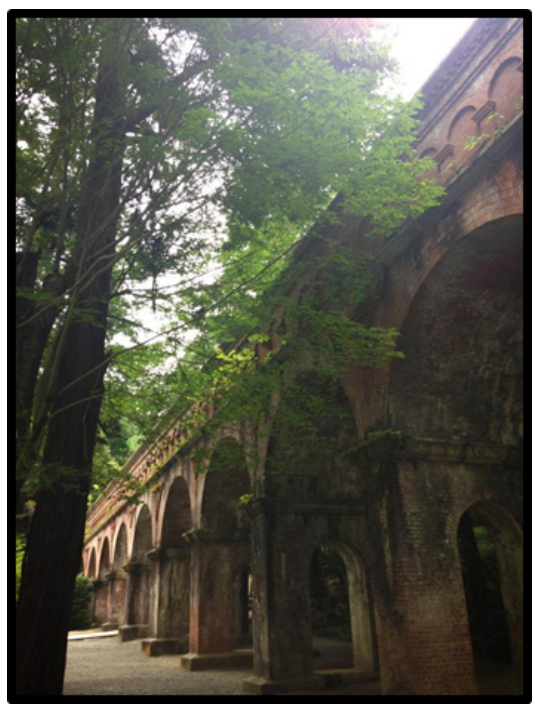

Fig. 2. Acueducto del Templo Nanzen-ji. 1890. Kioto. Foto: Daniel Sastre (2011). 
Un último aspecto de esta modernidad acabaría vinculándose posteriormente a la estrategia cultural que comentaremos más adelante. Es la tradición moderna de las Exposiciones Industriales, y que también se celebrarían en Kioto. ${ }^{14}$ Eventos que reunían bajo un mismo techo las técnicas más punteras para el hilado de la seda, la fundición de metales, etc. y que consiguieron en un periodo de casi diez años otorgar un nuevo uso a los espacios dejados vacíos en el Palacio Imperial y alrededores. El uso se tornaba público frente a la exclusividad antigua, aunque la razón principal de usar estos terrenos lejos de lo puramente práctico radicaba en "[el] tamaño y dignidad" del emplazamiento, en palabras de la empresa organizadora. ${ }^{15}$

Al entrar en la década de los años 80 del siglo XIX se acentúa la tendencia de revalorización de las tradiciones nativas frente a la importación indiscriminada de modos occidentales. ${ }^{16}$ Uno de los políticos nacidos en Kioto y de mayor relevancia del período Meiji, Iwakura Tomomi (岩倉具視, 1825-1883), asesor personal del emperador Meiji, estaba preocupado con el estado del palacio imperial en Kioto y escribía las siguientes líneas en 1883 dentro de un plan de preservación de la ciudad que elevó a las autoridades municipales: ${ }^{17}$

Heian-kyō es un lugar que fue fundado por el Emperador Kanmu y desde entonces ha pasado más de un milenio. Es una región de montañas y ríos exquisitos, adornada con grandes santuarios y templos famosos. Su gente conoce la propiedad y estima la frugalidad y simplicidad. La benevolencia del gobierno de los anteriores emperadores permanece incluso hoy en día. ${ }^{18}$

Iwakura continúa afirmando que "quizá es inevitable que la celebrada capital de mil años deba ser desolada abruptamente", aunque es una pena ya que es la única capital que nos queda de la Antigüedad. ${ }^{19}$ Preservar la ciudad sería para él un modo de expresar "piedad y reverencia por los antiguos emperadores" ${ }^{20}$. Finalmente, Iwakura defendía como argumento para la recuperación del Kioto moderno, que esta era famosa tanto dentro como fuera de sus fronteras por su belleza y la bondad de las costumbres de sus gentes. ${ }^{21}$

Su propuesta para el rejuvenecimiento de la ciudad consistía en traer a ella los ritos de entronización de la casa imperial. La imagen que se invocó en los consecuentes debates era la de Moscú como la ciudad simbólica donde se celebraba la coronación de los zares rusos frente a San Petersburgo como la capital administrativa. ${ }^{22}$ Traer dichos ritos para Iwakura era esencial para la política ya que a través del

14 Kuni Takeyuki (國雄行) (2004): “Tenrankai Jidai no Kaimaku”「博覧会時代の開幕」. En: Matsuo Masahito (ed.) (松尾正人): Meiji Isshin to Bunmei Kaika『明治維新と文明開化』Tokio: Yoshikawa Kōbunkan, pp.249250 .

15 Tseng, 2016: 99.

16 Pyle, Kenneth B. (1969): The New Generation in Meiji Japan. Problems of Cultural Identity. 1885-1895. Stanford: Stanford University Press.

17 Fujitani, Takashi (1996): Splendid Monarchy. Power and Pageantry in Modern Japan. Berkeley \& Los Angeles: California University Press, p.57.

18 Ibid., p. 59.

$19 \quad$ Ibid., p .57.

$20 \quad$ Ibid., p. 59.

21 Ibid., p. 57.

22 Ibid., p. 56. 
ellos el gobierno podía mantener la estabilidad del orden social. ${ }^{23} \mathrm{El}$ documento de Iwakura es relevante porque observamos cómo dibuja Kioto como distintivamente emblemática de la herencia imperial de Japón, y designaba los palacios como "tanto la encarnación física de esa herencia sacrosanta así como en lugares de ritos para la perpetuación activa de la misma". ${ }^{24}$ La propuesta de Iwakura sería compartida por el emperador Meiji y tras la revisión por los órganos de gobierno, en 1889 la Ley de la Casa Imperial estableció que los ritos de entronización imperiales se celebrasen en Kioto. ${ }^{25}$

Los objetos artísticos antiguos se estaban entendiendo durante la edad moderna japonesa como avales y garantes de la autoridad de la Casa Imperial y consecuentemente, del gobierno que respaldaba. La ciudad que los contenía adquiría entonces la misma función. Fujitani recuerda como "La restauración Meiji, después de todo, se había llevado a cabo en nombre del pasado, y los líderes del nuevo régimen a duras penas podrían desvestir de su cúmulo de recursos simbólicos a la ciudad que mejor los mostraba", ${ }^{26}$ a pesar del traslado del poder político a Tokio.

\section{Kioto, repositorio de la esencia nacional.}

La segunda estrategia que al hilo de este desarrollo del pensamiento político se produce para la re-invención de la ciudad de Kioto en los años 80 del siglo XIX, sería entonces el perfilamiento simbólico de la ciudad y sus alrededores (incluyendo a Nara) como el origen espiritual del país. Takagi Hiroshi ha analizado como desde la perspectiva de los historiadores del arte japonés se conceptualizará la ciudad de Kioto como el garante de la tradición, frente a la ciudad de Tokio dónde se concentran todos los esfuerzos para construir la nación moderna. ${ }^{27}$ Para sustentar esta idea se presentaba como una ciudad de tradición dónde reposaba su espíritu creativo. Kioto aparecía por medio de esta estrategia como el lugar que durante siglos había detentado el papel de protectora-preservadora del patrimonio cultural. ${ }^{28}$

Esta estrategia se basaba en la imagen pre-existente de Kioto. El ambiente cultural en la ciudad de Kioto durante el período Edo estaba muy desarrollado. Había múltiples academias donde se enseñaba pintura, allí residían muchos de los mejores artesanos en cerámica, textiles y laca del país, y existía toda una cultura de encuentros culturales, exposiciones y publicaciones que la establecían como la alternativa cultural a la hegemónica Edo durante este período. ${ }^{29}$

Kioto se había convertido en un lugar de peregrinaje cultural e histórico durante el período Edo. ${ }^{30}$ La progresiva facilidad en el viaje dio paso a un aumento de publicaciones relacionadas, tales como guías de viajes, mapas y descripciones de sus lugares famosos o meisho (名所). Meisho indica lugares famosos, pero que poseen

Ibid., p. .57.

Tseng, A. "Urban Parks...”, op. cit., p. 104.

Ibid., p. 111.

Fujitani, T. Splendid Monarchy..., op. cit. p.59.

Takagi, Hiroshi (高木博志) (2006): Kindai Tennō-sei to Koto (『近代天皇制と古都』) Tokio: Iwanami Shoten, pp.134-135.

28 Íbidem.

29 Mc Kelway, Matthew P. (2005): Traditions Unbound. Groundbreaking Artists of Eighteen Century Kyoto. San Francisco: Asian Art Museum \& Chong-Moon Lee Center for Asian Art and Culture.

30 Stavros, M. Kyoto... op. cit. p. 182. 
una acumulación de referencias culturales que son las que realmente los valoran positivamente. Toshio Watanabe ha indicado: "Tradicionalmente era más bien esta acumulación de referencias culturales las que constituían el factor importante cuando se jerarquizaba un paisaje particular. La gente derramaba lágrimas enfrente de un paisaje aburrido siempre que estuviese asociado a un poema conmovedor o una trágica historia que se pudiese evocar». ${ }^{31}$ La naturaleza delante de uno en ocasiones no daba la talla del relato construido en torno a ella.

Desde finales del siglo XVIII y el siglo XIX los artistas de ukiyo-e jugaron un papel dominante en la diseminación de estas imágenes orientadas hacia la descripción de los lugares famosos de Kioto mostrándolo como un lugar repleto de santuarios, templos y palacios, que ilustraban las historias de antaño. ${ }^{32}$ (Fig.3)

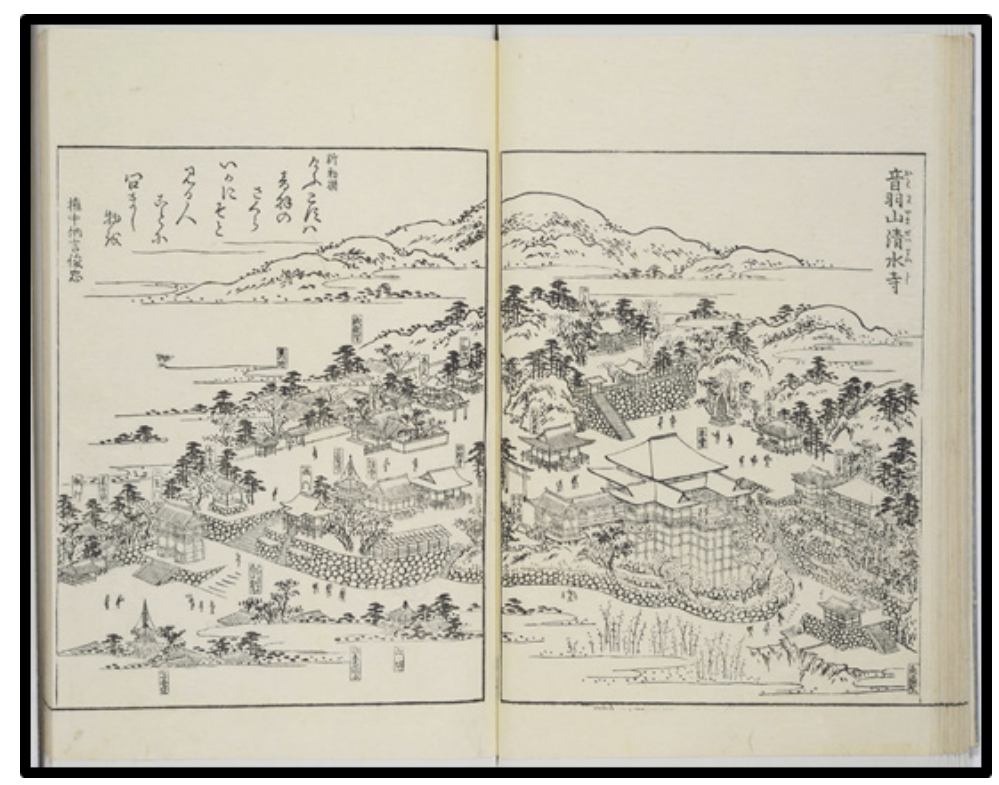

Fig. 03. Templo de Kiyomizudera. Miyako Meishozue. Vol.3. 1780. Reedición de 1786. Texto: Akisato Ritō (act.s.XVIII-s.XIX) Diseños: Takehara Shunchōsai (m.1801). Foto: Art Research Center. Universidad de Ritsumeikan, Kioto. Ebi Collection 0117.

Cuando las autoridades políticas de Meiji comenzaron las campañas de registro de bienes culturales durante los años 70 y 80, encontraron en la ciudad de Kioto ese lugar donde se custodiaban las antigüedades que ilustraban el pasado de la nación. ${ }^{33}$ Una mirada que se había configurado como habíamos visto durante todo el período Edo por medio de los proto-medios de masas. Diferentes expediciones de especialistas catalogaron a lo largo del país todos los tesoros que eran dignos de protección.

31 Watanabe, Toshio (2016): “A Kyoto garden renewal? From Meiji to Early Showa Period”. En: Pitelka, M. \& Tseng, A. (eds.), Kyoto ..., op. cit. p.165

32 Ibidem. Location number 4665. Pueden verse ejemplos en Fowler, Sherry (2008): "Views of Japanese Temples and Shrines from Near and Far: Precinct Prints of the Eighteenth and Nineteenth Century". En: Artibus Asiae. Vol.68, No 2, pp. 247-285.

33 Satō, Dōshin (2011): Modern Japanese Art and the Meiji State: The Politics of Beauty. Los Ángeles: Getty Research Institute, pp.52-54, 162-163. 
Quizá incluir un inciso para explicar que debido a la tremenda ley de desamortización de los bienes budistas, que se produce a principios del período Meiji, muchos bienes habían sido o bien destruidos, o bien vendidos al por mayor a vendedores extranjeros que estaban deseosos de adquirir estos productos tan exóticos a sus ojos. ${ }^{34}$

En la ciudad de Kioto las élites culturales, políticas y económicas de la ciudad colaboran desde el principio con las autoridades ya que la gran mayoría de los bienes culturales se encontraban o en la ciudad o en su vecindad. Preservar estos bienes, difundirlos a los ciudadanos y conservarlos harán que la ciudad desde muy pronto entienda que aquí tiene una oportunidad de regeneración e identificación frente a Tokio. Posee un carácter de repositorio nacional, de lugar donde los japoneses pueden acudir a entender lo que les hace grandes como nación y donde encontrarán ese espíritu que se ha transmitido de generación en generación, inmutable al cambio de los tiempos, como repetirá la retórica de la época Meiji.

El surgimiento así mismo de las disciplinas de la Historia y la Historia del Arte al estilo occidental, enseñadas en las instituciones que el Gobierno Meiji, que fue creando escuelas de bellas artes, universidades, y museos, contribuyeron a que surgiera una conciencia histórica que los japoneses del anterior período Edo no tenían.

Es en los cinco años que pivotan entre finales de la década de los 80 y el principio de los 90 del siglo XIX cuando se fija por parte de varios agentes culturales relacionados con empresas artísticas y de preservación de patrimonio, la división histórico-artística en periodos propuesta por Okakura Tenshin. Dicha periodización configura una imagen de la primera capital japonesa, Nara, como el locus del arte clásico japonés, y transforma a Kioto en la segunda capital, como el foco de la cultura autóctona, propia, japonesa, ${ }^{35}$ con rasgos propios que la diferencian de las producciones continentales y que dotan a cada una de ellas de su canon artístico. Son dos épocas de esplendor, dentro del esquema hegeliano de progresión civilizadora, y hace que la ciudadanía de Kioto empiece a identificarse con esta etapa de esplendor cultural.

Esto haría que la interpretación de los lugares de la ciudad cambiase. Takagi ha introducido la cuestión de la transformación en un "bien cultural importante" de la ciudad de Kioto en sí desde el punto de vista de los sitios famosos. ${ }^{36}$ Por ejemplo, nos describe cómo a principios del período Edo, en la guía de turismo a la ciudad titulada Kyōto Warabe『京都童』(1658) el edificio que simbolizaba al templo Tō-ji (東寺), era el Pabellón de Kōbō Daishi (Daishi-dōo, 大師堂) que está al oeste del recinto templario, y centro del culto de la figura del monje Kūkai (空海, 774-835), más conocido por su nombre póstumo de Kōbō Daishi desde el período Muromachi. ${ }^{37}$ También ha observado que a partir de la década de 1890, el templo se apreció desde un punto de vista estético, vinculándolo con la primera mitad del período Heian y el auge del budismo esotérico, asociándolo con la nobleza de las estatuas que configuran un mandala tridimensional y que son la imagen actual del conjunto templario de Tō-ji. ${ }^{38}$

34 Kambayashi, Tsunemichi (神林恒道) (2006): Kindai Nihon Bigaku no Tanjō.『近代日本「美学」の誕生』 Tokio: Kōdansha, 2006, pp.20-22. Ketelaar, James Edward (1993): Of Heretics and Martyrs in Meiji Japan. Buddhism and Its Persecution. Princeton: Princeton University Press, pp.54-65.

35 Takagi, Hiroshi (高木博志) (2005-2006): “Kindai Kyōto to Kokufū Bunka•Azuchi Momoyama Bunka”. 「近 代京都と国風文化·安土桃山文化」. En Jinbun (『人文』, N.53. Kioto, Universidad de Kioto, pp.13-14.

36 Ibid., p.14.

37 Íbidem.

38 Íbidem. 
También podemos decir lo mismo del edificio que Okakura estableció como símbolo de la "cultura nacional” (国風文化), del período Heian que constituye el Templo del Pabellón del Fénix en Uji. (Fig.4) Este edificio en el período moderno temprano se concebía dentro del mundo de la batalla del río Uji relatado en El Cantar de Heike. ${ }^{39}$ Sin embargo, a partir de la década de 1890 se le asoció a una "cultura nacional", propia, y no vinculada con lo extranjero, percepción que hizo que fuese un modelo perfecto para replicar en el pabellón japonés de la Exposición Universal de Chicago de 1893 representando de un modo puro a la cultura japonesa ${ }^{40}$. En palabras de Okakura: “(...) el patronazgo liberal de la familia Fujiwara conllevó un renacimiento de un gusto puramente japonés (...) un nuevo desarrollo en el arte y cultura japonesa la cual podría ser llamada la nacional, en contraste con las ideas predominantes continentales de las épocas precedentes". ${ }^{41}$

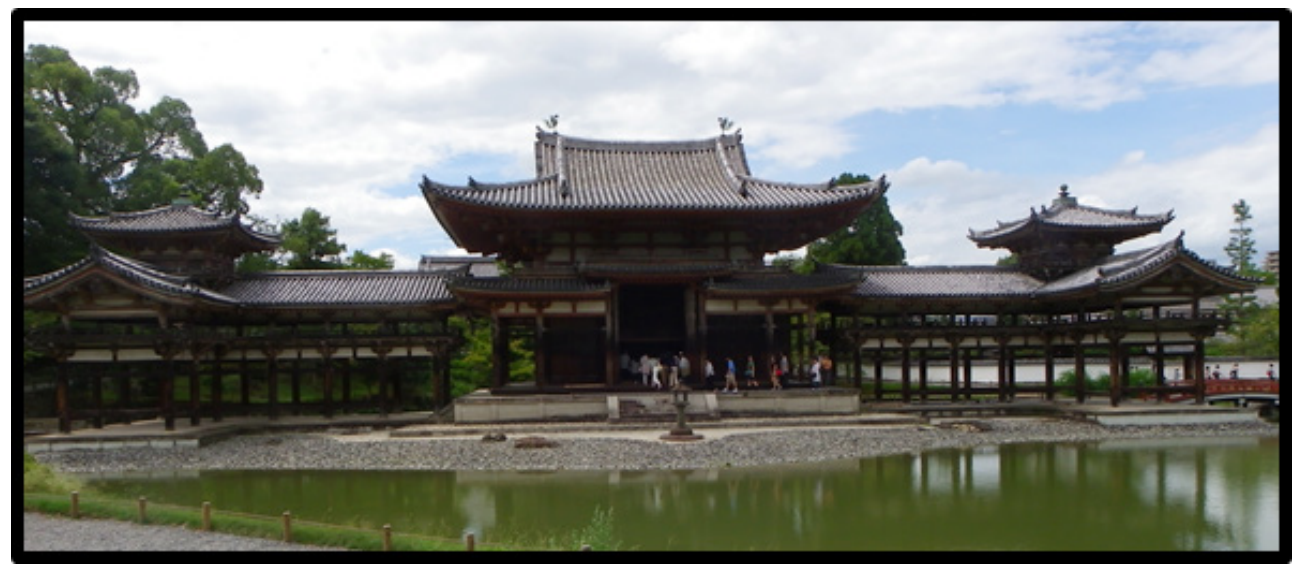

Fig. 4. Templo de Byōdō-in. Pabellón del Fénix. Uji, Prefectura de Kioto. 1052 d.C.

Foto: Daniel Sastre (2011)

Es decir, la concepción, difusión y promoción de una historia del arte nacional comenzó a manifestarse en el cambio de imagen de la ciudad de Kioto y sus monumentos no cómo exclusivamente simbólicas de la familia imperial y su herencia, sino como de museo imaginario de la historia del arte japonés. Los monumentos dejaban de ser exclusivamente templos o santuarios para pasar a ser ejemplos de un estilo o una época.

El momento más interesante de fusión de las dos estrategias, económica y cultural en la re-invención de la ciudad de Kioto se dio el año 1895 cuando se produjo el 1100 aniversario de la fundación de la ciudad por el Emperador Kanmu (桓武天 皇, 737-806). ${ }^{42}$ Aprovechando la efeméride se celebró en la ciudad la IV Exposición Nacional de Industria junto a la reconstrucción del Santuario de Heian, una réplica

\footnotetext{
39 Íbidem.

40 Snodgrass, Judith (2003): Presenting Japanese Buddhism to the West. Orientalism, Occidentalism and the West. North Carolina: University of North Carolina Press, p. 30.

${ }_{41}$ Citado por Snodgrass, Judith. Presenting..., op. cit. p.30. El énfasis también se encontraba señalado en el original de Okakura.

42 Tseng, A. "Urban Parks...", op. cit., pp. 106-107.
} 
reducida del edificio principal del palacio del Emperador Kanmu. ${ }^{43}$ (Fig.5) Aprovechando esta celebración el Ayuntamiento de la Ciudad adquirió el área adyacente de Okazaki y elevó una serie de edificios cívicos públicos tales como biblioteca, zoológico y museo que definían un parque público al mismo tiempo que lo asociaba con la presencia de la casa imperial identificada en la imponente construcción del Santuario de Heian. ${ }^{44}$ La exposición fue un gran éxito de público y los medios de la época lo promocionaron enormemente como un hito en el grado de progreso y civilización de la joven nación japonesa.

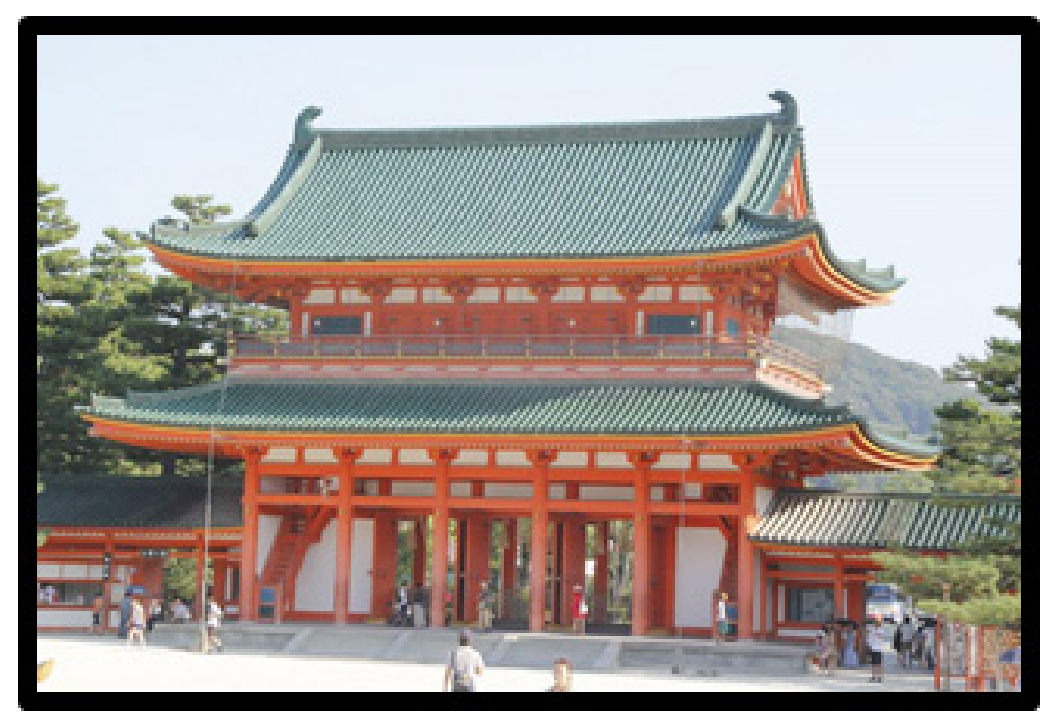

Fig. 5. Santuario de Heian. Puerta de tenmon. 1893-5. Itō Chūta (1867-1954). Kioto. 2013. Foto: Daniel Sastre.

Un paso importante fue la invitación que realizó el Consejo Municipal de la ciudad de Kioto al profesor de la Escuela de Bellas Artes de Tokio, Fukuchi Fukuichi (福地復一, 1862-1909) para que realizase un registro de los bienes culturales importantes de la época Heian que quedasen en la ciudad. ${ }^{45}$ Fruto de ello fue un documento con 62 obras del período Heian temprano, 56 obras de Heian medio y 41 obras del Heian final. En total, más de 150 obras entre las que se encontraba el Pabellón del Fénix de Uji. ${ }^{46}$ El movimiento oficial de incluir nuevos bienes culturales a proteger en los esfuerzos estatales de conservación de las producciones culturales del país reforzaba la posición de Kioto como repositorio de los preciados bienes de una época remota que, sin embargo, proyectaba riqueza como nación civilizada en el presente.

El último paso en nuestro examen del proceso del establecimiento final de la idea de Kioto como la ciudad que custodia el legado cultural japonés se produce cuando llegó a las aulas de los alumnos de educación primaria y secundaria. Junto con la

\footnotetext{
Tseng, A. "The Retirement...", op. cit., p. 216.

Tseng, A. "Urban Parks...," op. cit., p. 107.

Takagi, H. Kindai Tennō-sei..., op. cit. p.151.

46 Íbidem.
} 
aparición de un turismo histórico-artístico, muchas de las escuelas de la ciudad de Kioto y su vecindad, planearon viajes de graduación, o de estudio, donde se estudiaba el pasado de la nación japonesa a través de su legado artístico monumental. ${ }^{47}$

Esta tendencia terminará educando a toda una generación de ciudadanos en las ideas de historia del arte y la cultura, mientras que se configuraba un mapa común de lugares culturales, así como una historia y memoria compartidas. Como resultado de ello, aquellas piezas artísticas que se consideraba que contenían el espíritu, o la esencia japonesa se fueron canonizando progresivamente dentro de las aulas y se les fue añadiendo un valor objetivo de "tradición". Una consecuencia última de la instauración gubernamental de la política de los Tesoros Nacionales que habían ido primando la importancia de obras de arte específicas frente a otras. ${ }^{48}$

Los viajes de los estudiantes de primaria y secundaria que venían de todo el país han dejado como testimonios diarios que nos ayudan a comprender el enraizamiento de esta visión de Kioto como un referente de la nación, un reflejo del pasado, y un lugar donde reencontrarse con los antepasados comunes a todos los japoneses. Por ejemplo, una niña decía en 1902:

Se puede encontrar el Heian Jingū con sus réplicas del Daigokuden (Pabellón principal del palacio) y la puerta Ōtenmon (de acceso) que con sus columnas de color bermellón y verdes tejas nos hace imaginar convincentemente el Palacio Imperial en los tiempos de la Antigüedad. ${ }^{49}$

O en el anteriormente comentado Pabellón del Fénix, Takagi ha presentado el material de una estudiante de Akita que escribía en noviembre de 1910, en el viaje de fin de curso del instituto femenino de Nara, que junto con "pinturas de Yorimasa" y "arcos, sillas de montar, armaduras, naginata y todo tipo de objetos relevantes relacionados con la batalla del río Uji”, apreciaron la elegancia del pabellón del Fénix del "período de los Señores Fujiwara" y el Buda Amida del escultor Jōchō. ${ }^{50}$

Kioto iría configurando una imagen de su pasado glorioso en torno a dos épocas de esplendor. La primera sería la de su fundación y expansión como la capital de la era Heian (de los siglos IX al XII d.C.), y la segunda sería en el siglo XVI d.C. bajo el mandato de Toyotomi Hideyoshi, cuando la ciudad floreció y se llevaron a cabo diversos programas constructivos. En la época Meiji se acentuó la denominación de esta segunda época dorada como el "período Momoyama", y recibió al mismo tiempo una alta dosis de romanticismo. Esto se debió a la idea de que se reconocían como si se mirasen en un espejo, ya que a pesar de la gran distancia cronológica con aquella época, podían encontrarse elementos similares: una apertura internacional, una autoridad centralizada y una mayor libertad para las clases comerciantes, así como la próspera situación económica. ${ }^{51} \mathrm{Al}$ comparar el Japón del siglo XVI con el

47 Takagi, H. Kindai Tennō-sei..., op. cit. p.163.

48 Conant, Ellen. P. (2006) (ed.): Challenging Past and Present. The Metamorphosis of Nineteenth-Century Japanese Art. Honolulu: Hawai'i University Press, pp.16-17. Yiengpruksawan, Mimi Hall (2001): "Japanese Art History 2001: The State and Stakes of Research.” En: The Art Bulletin, Vol.53, N.1, March, pp. 103, 105-122.

$49 「 \ldots 」$ 平安神宮は大極殿に模し楼門を応天門に疑して作り碧瓦丹楹以て古の皇居を想像せしむるに足 る。Chiri Rekishi Kenkyūkai Ed.: (地理歴史研究会編) (1902) Nihon Zenkoku Junshu Gakusei Ensoku Shūgaku Ryokō Annai. (『日本全国巡遊学生遠足修学旅行案内』) Osaka: Tanaka Sōeido, p. 33.

so Takagi, H. "Kindai Kyōto...", op. cit., p. 14.

51 Takagi, H: Kindai Tennōsei ... op. cit. pp. 163-165. 
país cerrado controlado bajo el sogunado Tokugawa, el público japonés de la primera mitad de los mil novecientos del siglo XX quedó impresionado por la riqueza y multiculturalidad del arte nanban y su asociación al período Momoyama.

En el Kioto moderno se acabarían configurando entonces dos grandes imágenes, la de la elegancia, sensibilidad aristocrática, miyabi雅, de la época Heian, y la imagen de la clase comerciante urbana o machish $\bar{u}$ 町衆. ${ }^{52}$ Ambas están conectadas con las ideas de "cultura nacional" de Heian, y de la cultura del período Azuchi-Momoyama. Joshua Mostow ha demostrado cómo durante los años 30 del siglo XX, junto con el auge por el estudio de la novela La historia de Genji, se produjo la popularización de la idea de miyabi, ${ }^{53}$ y más tarde, durante el período de gran crecimiento económico de los años de posguerra, autores como Hayashiya Tatsusaburō (林屋辰 三郎) hablaron de la cultura urbana de los ciudadanos de Kioto. ${ }^{54}$

\section{Conclusión}

Finalmente, una reflexión sobre el proceso que experimenta la ciudad de Kioto en el período Meiji, cuando frente a la amenaza de desaparecer, o quedar "jubilada" en palabras de Alice Tseng, hemos observado cómo se reinventó en el adalid de la modernidad al mismo tiempo que explotando su asociación con la familia imperial se convertiría en el guardián y custodio de los tesoros de la nación japonesa. En cierto modo, Kioto se tornó en museo, se musealizó. Y en ese proceso, se convirtió ella en sí misma en un monumento. Nicolás Fiévé ha reflexionado sobre cómo "Los monumentos en general son herramientas para el reconocimiento de una autoridad política. De hecho, como las tradiciones, ellos son las manifestaciones de un deseo expresivo que pretende inscribirse a sí mismo en el paso del tiempo pero efectivo tan solamente porque pertenecen al presente". ${ }^{55}$ En este sentido, el gobierno Meiji encontró en la ciudad de Kioto un aliado perfecto en su vertebración de la nación japonesa. Narraba un lejano y glorioso pasado pero que servía a los objetivos y aspiraciones del presente desarrollado en el cambio del siglo XIX al XX.

Pero como también nos dice Françoise Choay:

[Monumento] ...del latín monumentum, a su vez derivado de monere (avisar, recordar), aquello que interpela a la memoria. La naturaleza afectiva de su vocación es esencial: no se trata de constatar cosa alguna ni, tampoco, de entregar una información neutra sino de suscitar, con la emoción, una memoria viva. (...) Ese pasado invocado, convocado, en una suerte de hechizo, no es cualquiera: ha sido localizado y seleccionado por motivos vitales, en tanto que puede contribuir directamente a mantener y preservar la identidad de una comunidad étnica, religiosa,

$52 \quad$ Ibid., p. 133-136.

53 Curiosamente, la palabra miyabi como tal no aparece en La Historia de Genji. Mostow, Joshua. (1999) "Nihon no Bijutsu-shi Gensetsu to Miyabi” (「日本の美術史言説と「みやび」) En: Tōkyō Kokuritsu Bunkazai Kenkyūjo (東京国立文化財研究所) (eds.), Kataru Genzai Katareru Kako: Nihon no Bijutsu-shigaku Hyakunen (『語 る現在語れる過去：日本の美術史学百年』) Tokio: Heibonsha, pp. 232-239. p. 232.

54 Takagi, H. Kindai Tennōsei... op. cit. p. 172.

55 Fiévé, Nicolas (2003): “Kyoto's Famous Places. Collective Memory and 'Monuments' in the Tokugawa Period”. En: Fiévé, N. / Walley, P. (eds.), Japanese Capitals in Historical Perspective. Place, Power and Memory in Kyoto, Edo and Tokyo. London \& New York: Routledge Curzon, p. 167. 
nacional, tribal o familiar. El monumento es, tanto para quienes lo edifican como para los que reciben sus mensajes, una defensa contra los traumatismos de la existencia, un dispositivo de seguridad. ${ }^{56}$

Kioto se manifiesta entonces como ese "pasado invocado", "seleccionado" en una doble necesidad de supervivencia frente a la pujanza de una Tokio cosmopolita, pero al mismo tiempo, con una función de representar una inequívoca esencia japonesa a sus habitantes y a los extranjeros. Asimismo, ¿no podríamos entonces considerar que Kioto parece haberse configurado como la mejor arma que en Meiji se elabora para resistir la traumática entrada de Japón en la modernidad mundial? Ese "dispositivo de seguridad" con el que guarecerse contra la superioridad de una cultura occidental omnipresente.

Lo que está fuera de toda duda es la extraordinaria efectividad de la instauración de Kioto como la antigua capital japonesa al entrar en el siglo XX. El lugar donde reencontrarse con el relato como nación y civilización del joven imperio. Cuando en las guías para extranjeros en torno a 1910 encontramos pasajes como este, observamos que la estrategia ha triunfado:

Escribir la historia de Kioto hasta el comienzo de nuestra era sería escribir toda la historia de Japón (...). ${ }^{57}$

56 Choay, Françoise (2007): Alegoría del Patrimonio. Barcelona, Editorial Gustavo Gili, S.L., pp. 12-13. A excepción de los términos en latín, las cursivas son nuestras.

57 The Kyoto Commercial Museum (1910): The Official Catalogue. Kioto: The Kyoto Commercial Museum, p.2. 